\title{
Evaluasi Penggunaan Supporting Applications For Quick Data Search (SuApQuDaS) Dengan Metode PIECES Framework
}

\author{
Yana Iqbal Maulana ${ }^{1}$, Agus Salim ${ }^{2}$ \\ 1,2Program Studi Sistem Informasi \\ Universitas Bina Sarana Infromatika \\ 1yana.yim@bsi.ac.id, 2agus.salim@bsi.ac.id
}

\begin{abstract}
ABSTRAK. Aplikasi SuApQuDaS dibangun untuk memenuhi kebutuhan tim di salah satu biro dalam mengelola data khususnya proses pencarian data untuk meningkatkan pelayanan kepada customer. Evaluasi merupakan kegiatan terencana untuk menilai suatu permasalahan yang terjadi dengan menggunakan instrumen dan hasilnya dapat dibandingkan dengan tolak ukur untuk memperoleh kesimpulan sehingga ditemukan solusi untuk menyelesaikan permasalahan yang timbul. Sedangkan Evaluasi sistem informasi dapat dilakukan dengan cara yang berbeda dan pada tingkatan yang berbeda, tergantung pada tujuan evaluasinya. Tujuannya adalah untuk menilai kemampuan teknis, pelaksanaan operasional, dan pendayagunaan sistem. Untuk mempermudah evaluasi, ditawarkan cara analisis dengan kerangka PIECES yang menguraikan ke dalam 6 fokus analisis kelemahan yaitu Performance, Information and Data, Economy, Control and Security, Eficiency dan Service. Berdasarkan metode analisis kerangka kerja PIECES dalam mengukur tingkat evaluasi didapatkan nilai dari masing- masing domain yaitu domain performance memperoleh skor 4,09, domain information and data memperoleh skor 4,18, domain economics memperoleh skor 4,18, domain control and security memperoleh skor 4,11, domain efficiency memperoleh skor 4,17, dan domain service memperoleh skor 4,13.
\end{abstract}

Kata Kunci: PIECES, Framework, Evaluasi, Likert, SuApQuDaS

\begin{abstract}
The SuApQuDaS application was built to meet the needs of a team in one of the bureaus in managing data, especially the data search process to improve service to customers. Evaluation is a planned activity to assess a problem that occurs using instruments and the results can be compared with benchmarks to obtain conclusions so that solutions can be found to solve problems that arise. Meanwhile, information system evaluation can be carried out in different ways and at different levels, depending on the purpose of the evaluation. Its purpose is to assess technical capabilities, operational implementation, and system utilization. To simplify the evaluation, an analysis method is offered with the PIECES framework which describes the 6 focus of weakness analysis, namely Performance, Information and Data, Economy, Control and Security, Efficiency and Service. Based on the analysis method of the PIECES framework in measuring the level of evaluation, the value of each domain is obtained, namely the performance domain gets a score of 4.09, the domain information and data gets a score of 4.18, the domain economics gets a score of 4.18, the domain control and security gets a score 4.11, domain efficiency gets a score of 4.17, and domain service gets a score of 4.13.
\end{abstract}

Keywords: PIECES, Framework, Evaluation, Likert, SuApQuDaS

\section{PENDAHULUAN}

Aplikasi SuApQuDaS dibangun untuk memenuhi kebutuhan tim di salah satu biro dalam mengelola data khususnya proses pencarian data untuk meningkatkan pelayanan kepada customer.

An information system is a set of interrelated components that collect, process, store, and provide as output the information needed to complete business tasks (Satzinger, Jackson, \& Burd, 2016). Information technology (IT) refers to the combination of hardware, software, and services that people use to manage, communicate, and share information (Tilley \& Rosenbalt, 2017).

Evaluasi merupakan kegiatan terencana untuk menilai suatu permasalahan yang terjadi dengan menggunakan instrumen dan hasilnya dapat dibandingkan dengan tolak ukur untuk memperoleh kesimpulan sehingga ditemukan solusi untuk menyelesaikan permasalahan yang timbul. Sedangkan Evaluasi sistem informasi dapat dilakukan dengan cara yang berbeda dan pada tingkatan yang berbeda, tergantung pada tujuan evaluasinya. Tujuannya adalah untuk menilai kemampuan teknis, pelaksanaan operasional, dan pendayagunaan sistem (Supriyatna \& Maria, 2018).

Evaluasi sistem informasi dapat dilakukan dengan cara berbeda dan pada tingkatan berbeda, tergantung pada tujuan evaluasinya. Evaluasi bermanfaat untuk mengetahui bagaimana implementasi suatu sistem telah dijalankan. Ada banyak evaluasi yang dapat dilakukan terhadap informasi, yaitu evaluasi pra-implementasi, evaluasi review implementasi, evalusi operasional (Agustina, 2018).

Dalam melakukan kegiatan analisis dan evaluasi sistem informasi terdapat beberapa metode atau model analisis yang dapat digunakan, salah satunya adalah model analisis PIECES Framework. Untuk mempermudah 
evaluasi, ditawarkan cara analisis dengan kerangka PIECES yang menguraikan ke dalam 6 fokus analisis kelemahan yaitu performance, information and data, economy, control and security, eficiency, dan service (Supriyatna \& Maria, 2018).

\section{METODE PENELITIAN}

PIECES framework adalah kerangka yang dipakai untuk mengklasifikasikan suatu problem, opportunities, dan directives yang terdapat pada bagian scope definition analisis dan perancangan sistem. Dengan kerangka ini, dapat dihasilkan hal- hal baru yang dapat menjadi pertimbangan dalam mengembangkan sistem (Supriyatna \& Maria, 2018).

Dalam PIECES terdapat enam buah variabel yang digunakan untuk menganalisis sistem informasi, yaitu (Supriyatna \& Maria, 2018):

a. Performance (Keandalan)

Analisis ini dilakukan untuk mengetahui kinerja sebuah sistem, apakah berjalan dengan baik atau tidak. Kinerja ini dapat diukur dari jumlah temuan data yang dihasilkan dan seberapa cepat suatu data dapat ditemukan.

b. Information and Data (Data dan Informasi)

Dalam sebuah temuan data pasti akan dihasilkan sebuah informasi yang akan ditampilkan, analisis ini digunakan untuk mengetahui seberapa banyak dan seberapa jelas informasi yang akan dihasilkan untuk satu pencarian.

c. Economics (Nilai Ekonomis)

Analisis ini dilakukan untuk mengetahui apakah suatu sistem itu tepat diterapkan pada suatu lembaga informasi dilihat dari segi finansial dan biaya yang dikeluarkan. Hal ini sangat penting karena suatu sistem juga dipengaruhi oleh besarnya biaya yang dikeluarkan.

d. Control and Security (Pengendalian dan Pengamanan)

Dalam suatu sistem perlu diadakan sebuah kontrol atau pengawasan agar sistem itu berjalan dengan baik. Analisis ini digunakan untuk mengetahui sejauh mana pengawasan dan kontrol yang dilakukan agar sistem tersebut berjalan dengan baik.

e. Efficiency (Efisiensi)

Efisiensi dan efektivitas sebuah sistem perlu dipertanyakan dalam kinerja dan alasan mengapa sistem itu dibuat. Sebuah sistem harus bisa secara efisien menjawab dan membantu suatu permasalahan khususnya dalam hal otomasi. Analisis ini dilakukan untuk mengetahui apakah suatu sistem itu efisien atau tidak, dengan input yang sedikit bisa menghasilkan sebuah output yang memuaskan.

f. Service (Pelayanan)

Dalam hal pemanfaat suatu sistem, sebuah pelayanan masih menjadi suatu hal yang penting dan perlu diperhatikan. Suatu sistem yang diterapkan akan berjalan dengan baik dan seimbang bila diimbangi dengan pelayanan yang baik juga. Analisis ini digunakan untuk mengetahui bagaimana pelayanan yang dilakukan dan mengetahui permasalahan- permasalahan yang ada terkait tentang pelayanan.

Dalam mendapatkan hasil evalusi yang diinginkan maka diperlukan metode pengukuran. Skala kuestioner untuk memberikan pertanyaan maupun pernyataan untuk repsonden dengan menggunakan skala linkert dengan memberikan skor dari jawaban repsonden (Agustina, 2018).

Table 1. Skala Likert

\begin{tabular}{ccc}
\hline Jawaban & Akronim & Skor \\
Sangat Setuju & SS & 5 \\
Setuju & S & 4 \\
Ragu-ragu & RG & 3 \\
Tidak Setuju & TS & 2 \\
Sangat Tidak Setuju & STS & 1 \\
\hline
\end{tabular}


Dalam menentukan nilai rata-rata dari setiap pernyataan yang telah diisi oleh responden harus di cari terlebih dahulu nilai dari interval kelasnya dalam menentukan nilai kepuaasan terhadap sistem penjualan tanaman obat. Berikut adalah rumus untuk mencari interval kelas dan nilai rata-rata (Komarudin, 2017).

\subsection{Rumus menentukan interval kelas}

$$
i=\frac{r}{k}
$$

$\mathrm{i}=$ Interval kelas

$r=$ Range (Nilai tertinggi - Nilai terendah)

$\mathrm{k}=$ Jumlah kelas

\subsection{Rumus menentukan nilai rata-rata}

$$
r=\frac{f}{n}
$$

$\mathrm{r}=$ nilai rata-rata

$\mathrm{f}=$ Frekuensi

$\mathrm{n}=$ Jumlah Responden

Table 2. Nilai Karakteristik Kepuasan

\begin{tabular}{cc}
\hline Skala & Ketegori Penilaian \\
$1.00-1.80$ & Sangat Buruk \\
$1.81-2.61$ & Buruk \\
$2.62-3.42$ & Cukup \\
$3.43-4.23$ & Baik \\
$4.24-5.04$ & Sangat Baik \\
\hline
\end{tabular}

Tabel 3. Rekap keseluruhan total nilai skor domain

\begin{tabular}{ccc}
\hline Pilihan Jawaban & Singkatan & Skor \\
Sangat Setuju & SS & 5 \\
Setuju & S & 4 \\
Ragu-ragu & RG & 3 \\
Tidak Setuju & TS & 2 \\
Sangat Tidak Setuju & STS & 1
\end{tabular}

\section{HASIL DAN PEMBAHASAN}

Dari data-data kuesioner yang telah di isi responden sebagai pengguna SuApQuDaS, dimana semua responden tersebut sebagai pengguna SuApQuDaS, maka didapat hasil analisis terhadap SuApQuDaS. Datadata kuesioner tersebut direkapitulasi dan dihitung menggunakan rumus interval kelas dan rata- rata nilai kemudian diukur berdasarkan nilai karakteristik kepuasan pada masing-masing domain dari metode analisis PIECES Framework, berikut adalah hasil perhitungan analisis tingkat kepuasan pada pengguna SuApQuDaS:

\subsection{Hasil pengolahan dan analisis data terhadap domain Performance (Keandalan)}

Pada domain Performance terdapat 7 (tujuh) pernyataan. Adapun hasil dari pengolahan data dari masing-masing pernyataan adalah sebagai berikut :

Table 4. Hasil perhitungan Performance (Keandalan)

\begin{tabular}{|c|c|c|c|c|c|}
\hline \multirow{2}{*}{ Performance } & \multicolumn{5}{|c|}{ JUMLAH } \\
\cline { 2 - 6 } & SS & S & RG & TS & STS \\
\hline Question 1 & 6 & 12 & 2 & 0 & 0 \\
\hline Question 2 & 4 & 16 & 0 & 0 & 0 \\
\hline Question 3 & 5 & 13 & 2 & 0 & 0 \\
\hline Question 4 & 3 & 17 & 0 & 0 & 0 \\
\hline Question 5 & 4 & 13 & 1 & 2 & 0 \\
\hline
\end{tabular}




\begin{tabular}{|c|c|c|c|c|c|}
\hline Question 6 & 1 & 18 & 1 & 0 & 0 \\
\hline Question 7 & 1 & 17 & 2 & 0 & 0 \\
\hline \multicolumn{7}{|l|}{ Performance } & TK & TS & NK & KP \\
\hline Question 1 & 20 & 84 & 4.2 & Baik \\
\hline Question 2 & 20 & 84 & 4.2 & Baik \\
\hline Question 3 & 20 & 83 & 4.15 & Baik \\
\hline Question 4 & 20 & 83 & 4.15 & Baik \\
\hline Question 5 & 20 & 79 & 3.95 & Baik \\
\hline Question 6 & 20 & 80 & 4 & Baik \\
\hline Question 7 & 20 & 79 & 3.95 & Baik \\
\hline
\end{tabular}

\subsection{Hasil pengolahan dan analisis data terhadap domain Information and Data (Data dan Informasi)}

Pada domain Information and Data terdapat 5 (lima) pernyataan. Adapun hasil dari pengolahan data dari masing-masing pernyataan adalah sebagai berikut :

Table 5. Hasil perhitungan Information and Data (Data dan Informasi)

\begin{tabular}{|c|c|c|c|c|c|}
\hline \multirow{2}{*}{ Information and Data } & \multicolumn{5}{|c|}{ JUMLAH } \\
\cline { 2 - 7 } & SS & S & RG & TS & STS \\
\hline Question 1 & 3 & 17 & 0 & 0 & 0 \\
\hline Question 2 & 5 & 12 & 3 & 0 & 0 \\
\hline Question 3 & 7 & 11 & 2 & 0 & 0 \\
\hline Question 4 & 5 & 13 & 2 & 0 & 0 \\
\hline Question 5 & 7 & 11 & 2 & 0 & 0 \\
\hline \multicolumn{7}{|l|}{} \\
\hline Information and Data & TK & TS & NK & KP \\
\hline Question 1 & 20 & 83 & 4.15 & Baik \\
\hline Question 2 & 20 & 82 & 4.1 & Baik \\
\hline Question 3 & 20 & 85 & 4.25 & Sangat Baik \\
\hline Question 4 & 20 & 83 & 4.15 & Baik \\
\hline Question 5 & 20 & 85 & 4.25 & Sangat Baik \\
\hline
\end{tabular}

\subsection{Hasil pengolahan dan analisis data terhadap domain Economics (Nilai Ekonomis)}

Pada domain Economic terdapat 2 (dua) pernyataan. Adapun hasil dari pengolahan data dari masingmasing pernyataan adalah sebagai berikut :

Table 6. Hasil perhitungan Economics (Nilai Ekonomis)

\begin{tabular}{|c|c|c|c|c|c|c|}
\hline \multirow{2}{*}{ Economics } & \multicolumn{6}{|c|}{ JUMLAH } \\
\hline & SS & $\mathbf{S}$ & $\mathbf{R}$ & & TS & STS \\
\hline Question 1 & 3 & 17 & 0 & & 0 & 0 \\
\hline Question 2 & 6 & 12 & 2 & & 0 & 0 \\
\hline Economics & TK & $\mathbf{T}$ & & NF & & $\mathbf{K P}$ \\
\hline Question 1 & 20 & 8 & & 4.1 & & Baik \\
\hline Question 2 & 20 & 8 & & 4.2 & & Baik \\
\hline
\end{tabular}




\subsection{Hasil pengolahan dan analisis data terhadap domain Control and Security (Pengendalian dan} Pengamanan)

Pada domain Control and Security terdapat 5 (lima) pernyataan. Adapun hasil dari pengolahan data dari masing-masing pernyataan adalah sebagai berikut :

Table 7. Hasil perhitungan Control and Security (Pengendalian dan Pengamanan)

\begin{tabular}{|c|c|c|c|c|c|}
\hline \multirow{2}{*}{ Control And Security } & \multicolumn{7}{|c|}{ JUMLAH } \\
\cline { 2 - 7 } & SS & S & RG & TS & STS \\
\hline Question 1 & 6 & 13 & 1 & 0 & 0 \\
\hline Question 2 & 2 & 17 & 1 & 0 & 0 \\
\hline Question 3 & 3 & 17 & 0 & 0 & 0 \\
\hline Question 4 & 2 & 16 & 2 & 0 & 0 \\
\hline Question 5 & 2 & 18 & 0 & 0 & 0 \\
\hline \multicolumn{7}{|c|}{} \\
\hline Control And Security & TK & TS & NK & KP \\
\hline Question 1 & 20 & 85 & 4.25 & Sangat Baik \\
\hline Question 2 & 20 & 81 & 4.05 & Baik \\
\hline Question 3 & 20 & 83 & 4.15 & Baik \\
\hline Question 4 & 20 & 80 & 4 & Baik \\
\hline Question 5 & 20 & 82 & 4.1 & Baik \\
\hline
\end{tabular}

\subsection{Hasil pengolahan dan analisis data terhadap domain Efficiency (Efisiensi)}

Pada domain Efficiency terdapat 3 (tiga) pernyataan. Adapun hasil dari pengolahan data dari masingmasing pernyataan adalah sebagai berikut :

Table 8. Hasil perhitungan Efficiency (Efisiensi)

\begin{tabular}{|c|c|c|c|c|c|}
\hline \multirow{2}{*}{ Efficiency } & \multicolumn{5}{|c|}{ JUMLAH } \\
\hline & SS & $\mathbf{S}$ & RG & TS & STS \\
\hline Question 1 & 5 & 11 & 4 & 0 & 0 \\
\hline Question 2 & 4 & 14 & 2 & 0 & 0 \\
\hline Question 3 & 7 & 13 & 0 & 0 & 0 \\
\hline Efficiency & TK & TS & NK & & $\mathbf{P}$ \\
\hline Question 1 & 20 & 81 & 4.05 & & lik \\
\hline Question 2 & 20 & 82 & 4.1 & & \\
\hline Question 3 & 20 & 87 & 4.35 & Sang & t Baik \\
\hline
\end{tabular}

3.6. Hasil pengolahan dan analisis data terhadap domain Service (Pelayanan)

Pada domain Service terdapat 2 (dua) pernyataan. Adapun hasil dari pengolahan data dari masingmasing pernyataan adalah sebagai berikut :

Table 9. Hasil perhitungan Service (Pelayanan)

\begin{tabular}{|c|c|c|c|c|c|}
\hline \multirow{2}{*}{ Service } & \multicolumn{5}{|c|}{ JUMLAH } \\
\hline & SS & $\mathbf{S}$ & RG & TS & STS \\
\hline Question 1 & 4 & 15 & 1 & 0 & 0 \\
\hline Question 2 & 4 & 14 & 2 & 0 & 0 \\
\hline Service & TK & & TS & NK & $\mathbf{K P}$ \\
\hline Question 1 & 20 & & 3 & 4.15 & Baik \\
\hline
\end{tabular}




\begin{tabular}{|l|l|l|l|l|} 
Question 2 & 20 & 82 & 4.1 & Baik \\
\hline
\end{tabular}

Dari pengolahan dan analisa keseluruhan domain Evaluasi Penggunaan Supporting Applications For Quick Data Search (SuApQuDaS) Dengan Metode PIECES Framework dapat ditarik kesimpulannya sebagai berikut:

Tabel 10. Rekap keseluruhan total nilai skor domain

\begin{tabular}{ccc}
\hline Domain & Rata-rata & Kategori \\
Performance & 4,09 & Baik \\
Information and Data & 4,18 & Baik \\
Economics & 4,18 & Baik \\
Control and Security & 4,11 & Baik \\
Efficiency & 4,17 & Baik \\
Service & 4,13 & Baik \\
\hline
\end{tabular}

\section{KESIMPULAN DAN SARAN}

Berdasarkan hasil perhitungan data terhadap responden pada Evaluasi Penggunaan Supporting Applications For Quick Data Search (SuApQuDaS) Dengan Metode PIECES Framework, maka dapat disimpulkan menjadi beberapa bagian, yaitu: berdasarkan metode analisis kerangka kerja PIECES dalam mengukur tingkat evaluasi didapatkan nilai dari masing- masing domain yaitu domain performance memperoleh skor 4,09, domain information and data memperoleh skor 4,18, domain economics memperoleh skor 4,18, domain control and security memperoleh skor 4,11, domain efficiency memperoleh skor 4,17, dan domain service memperoleh skor 4,13.

Dalam penelitian ini, masih terdapat banyak kekurangan yang dapat diperbaiki untuk pengembangan berikutnya. Diharapkan Evaluasi Penggunaan Supporting Applications For Quick Data Search (SuApQuDaS) tidak hanya menggunakan metode PIECES Framework saja tapi bisa lebih dikembangkan lagi.

\section{DAFTAR RUJUKAN}

Agustina, N. (2018). Evaluasi Penggunaan Sistem Informasi ERP Dengan Metode Pieces Framework. Jurnal Informatika, 5(2), 278-286.

Komarudin, R. (2017). Analisis Sistem Informasi Penjualan Tanaman Obat Berbasis Web Dengan Metode Pieces Framework. Jurnal Bianglala Informatika, 5(1), 14-20.

Satzinger, J. W., Jackson, R. B., \& Burd, S. D. (2016). Systems Analysis and Design in a Changing World (7th ed.). USA: Cengage Learning.

Supriyatna, A., \& Maria, V. (2018). Analisis Tingkat Kepuasan Pengguna dan Tingkat Kepentingan Penerapan Sistem Informasi DJP Online dengan Kerangka PIECES. Khazanah Informatika: Jurnal Ilmu Komputer Dan Informatika, 3(2), 88-94.

Tilley, S., \& Rosenbalt, H. (2017). Systems Analysis and Design (11th ed.). USA: Cengage Learning. 